\title{
As tecnologias de reprodução assistida e as representações sociais de filho biológico
}

\author{
Ana Maria Monteiro Borlot \\ Zeidi Araújo Trindade \\ Universidade Federal do Espírito Santo
}

\begin{abstract}
Resumo
Foram investigadas as representações sociais de filho biológico em casais que se submeteram às tecnologias reprodutivas. Nossos objetivos foram analisar a trajetória de vida do casal a partir do momento em que foi constatada a infertilidade e identificar as representações sociais de filho biológico. Cinco casais da Grande Vitória, ES foram entrevistados e nenhum deles havia obtido êxito com relação à gravidez após o tratamento. As entrevistas semi-estruturadas foram realizadas individualmente. O roteiro seguiu o mesmo padrão para ambos os cônjuges, incluindo itens sobre a constatação da infertilidade, o tratamento realizado, o significado da maternidade, paternidade, casamento e filho biológico. A análise dos resultados apontou para um fortalecimento do vínculo no casamento após o diagnóstico de infertilidade e evidenciou a importância que os casais atribuem ao filho biológico. Os elementos de representações sociais que apareceram fortemente foram: “sangue do meu sangue”, descendência, semelhança física e pressão social.
\end{abstract}

Palavras-chave: tecnologias reprodutivas; representações sociais; filho biológico

\begin{abstract}
The reproductive technologies and the social representations of biological children. Social representations of biological child in couples who underwent reproductive treatment were studied. Our objectives were to analyze the life trajectory of the couple from the moment infertility was diagnosed and identify the social representations of biological children. Five couples of Great Vitória (Espírito Santo State, Brazil) were interviewed and none of them had success with respect to pregnancy. We used semi-structured interviews, individually taken. The script followed the same pattern for both the man and the woman, including items about the acceptance of the infertility diagnosis, the kind of treatment, the meaning of motherhood, fatherhood, marriage and biological child. The analysis of the results pointed to a strengthening of the bond in the marriage after the acceptance of the infertility diagnosis and highlighted the importance that couples attribute to the biological child. The elements of social representation which appear prominently were: "sangue do meu sangue” (expression equivalent to "my own flesh and blood”), progeny, physical resemblance, social pressure.
\end{abstract}

Key words: reproductive technologies; social representations; biological child

A lgumas mudanças ocorridas na sociedade, principal mente em relação ao papel da mulher, têm contribuído para uma queda nas taxas de fecundidade tanto no Brasil quanto em outros países. Muitas mulheres estão empenhadas em reduzir o número de filhos e em deixar para mais tarde a experiência de ser mãe, uma vez que possuem outros interesses que ultrapassam a vida restrita ao âmbito doméstico, além de perceberem a maternidade como geradora de um grande custo para sua vida (problemas de saúde, ausência dos homens na criação dos filhos, entre outros). Segundo Collucci (2000), a gravidez após os trinta e cinco anos cresceu na última década oitenta e quatro por cento nos Estados Unidos. A autora aponta que, no Brasil, apesar de existirem poucas estatísticas sobre o assunto, esta tendência tem sido confirmada. Uma pesquisa da empresa Maplan “feita em 1998 em nove capitais brasileiras, mostra que, em dez anos, a proporção de mulheres que têm filhos entre 30 e 44 anos subiu de 30\% para 41\%” (p. 63).

Podemos perceber que algumas mudanças já aconteceram no comportamento das mulheres, como a opção por ter menos filhos e o adiamento do momento da gravidez que, segundo Corrêa (2001), são decisões geralmente exigidas por "fatores como a formação prolongada, a busca de equilíbrio financeiro doméstico etc.” (p. 189). Entretanto, para grande parte das mulheres, a maternidade continua sendo a meta de sua vida. Sendo assim, muitas mulheres que não podem gerar um filho sentem-se insatisfeitas, sofrem e geralmente procuram tratamento contra infertilidade (Arilha, 1996). 
O projeto de constituir família com filhos não é exclusivo das mulheres. Muitos homens também possuem tal objetivo. Ao tentar concretizá-lo, alguns se deparam com a infertilidade e esta notícia deixa a maioria deles bastante abalada, principalmente pela dificuldade que têm de entender que a infertilidade não está atrelada à virilidade (Collucci, 2000).

A opção por uma gestação mais tardia pode acarretar alguns dilemas. Souza (1995) evidencia que "muitas mulheres que adiaram ou colocaram de lado seus projetos de terem filhos agora se agarram a ele com unhas e dentes” (p. 77). Estas mulheres, segundo a mesma autora, encontram respaldo nas inúmeras ofertas de tratamentos para esse fim: “O mercado de tecnologias reprodutivas fomenta uma verdadeira obsessão pelo projeto maternidade (elaborado numa linguagem de direitos), reforça a importância do parentesco biológico e a comercialização das relações pessoais” (p. 78).

Nesse sentido, Corrêa (2001) argumenta que há uma grande oferta de tecnologias médicas de reprodução oferecidas aos casais e há ainda uma pressão para o consumo de meios e de serviços médicos, podendo acarretar uma "incapacidade de suportar certo atraso na chegada de uma gravidez” (p. 190). Além disso, “a ausência de filhos passaria a ser abordada como uma patologia: redefinição promovida a partir dos novos métodos de tratamento propostos pela própria medicina” (p. 14).

A valorização da procriação, principalmente em função de uma necessidade intrínseca à mulher, já é antiga. Muitos povos, desde a Antigüidade, valorizavam e enalteciam as mulheres que eram capazes de reproduzir, enquanto as inférteis eram excluídas e a infertilidade era vista como um castigo (Tanaka \& Alvarenga, 1999). Segundo estas autoras, existe um preconceito na área da obstetrícia e da ginecologia, em que o anatômico e fisiológico do homem se sobrepõem à psiqué da mulher e o corpo desta passa a ser visto como “canal de parto”. Afirmam que esse estereótipo ainda está presente em nossos dias e que os estudos de infertilidade, de aborto e de má formação fetal encontram-se

centrados em exposição de risco de saúde da mulher como se o homem fosse inócuo neste processo. Isto é, a fertilidade masculina nunca é posta à prova, o aborto é uma questão puramente feminina e as anomalias congênitas são sempre por problemas relacionados à mulher. (p. 203)

A idéia de que cabe à mulher a responsabilidade pela procriação encontra-se presente na sociedade de uma maneira geral e a infertilidade apresenta-se, para muitas delas, como um peso substancial, gerando sentimentos de culpa e autoconceito negativo, já que seu papel é tido como biologicamente definido e caracterizado pela maternidade. Tubert (1996) aponta que a valorização da maternidade modifica-se ao longo da história em função dos interesses econômicos, demográficos, políticos e outros. No entanto, a autora considera que nas sociedades patriarcais "a mulher entra na ordem simbólica somente sendo mãe” (p. 105).

Rocha-Coutinho (1994) expõe que o casamento, na modernidade, passou a ser baseado no amor e na liberdade de escolha e a maternidade converteu-se na "atividade mais invejável e doce que uma mulher pode esperar” (p. 36).

O processo de socialização dá-se diferentemente para homens e para mulheres e as convenções sócio-culturais determinam quais os papéis que cada um deve representar. Nesse sentido, Fonseca (1998) afirma que "os atos de conceber e criar filhos constituem experiências humanas atribuídas culturalmente às mulheres, incluindo muito discretamente o pai” (p. 186).

Apesar da maior responsabilização dirigida às mulheres quando o assunto é a geração de filhos, a dificuldade em consegui-los costuma atingir ambos os cônjuges, posto que é uma situação que geralmente afeta o relacionamento do casal. Além disso, a cobrança por parte da sociedade é dirigida aos dois, embora de maneiras diferentes. Em relação ao homem, a cobrança é no sentido de sua masculinidade; quanto à mulher, é relacionada à sua completude, ou seja, para ser uma mulher completa, ela deve ser mãe.

A infertilidade tem sido definida pela Organização Mundial de Saúde (OMS) como a incapacidade de um casal conseguir a gravidez ou o parto de um bebê vivo após um ano de relações sexuais regulares sem o uso de métodos anticoncepcionais, aumentando sua possibilidade de ocorrência com a idade, sendo que um em cada quatro casais com mais de 35 anos sofrerá de infertilidade (Schaffer \& Diamond, 1994).

No entanto, a noção de saúde e de direitos reprodutivos é bastante recente na esfera pública brasileira. Originou-se na década de 80 do século XX, com um movimento que se definiu pela saúde da mulher. Em meados daquela década, foram criados o Conselho Nacional de Estudos dos Direitos de Reprodução Humana no Ministério da Saúde e o PAISM - Programa de Assistência Integral à Saúde da Mulher (Ávila \& Corrêa, 1999).

Um marco na história da reprodução humana no Brasil foi o anúncio do nascimento do primeiro bebê de proveta brasileiro em 1984, seis anos após o nascimento do primeiro bebê por fertilização in vitro no mundo (Inglaterra), marcando a entrada do Brasil na modernidade da revolução tecnológica da biomedicina (Corrêa, 2001).

A reprodução assistida, produto dos avanços tecnológicos na área da saúde reprodutiva, é definida por Corrêa (2001) como "um conjunto de técnicas de tratamento médico paliativo, em condições de in/hipofertilidade humana, visando à fecundação” (p. 11). Tais técnicas substituem a relação sexual na reprodução biológica, provocando mudanças nos moldes tradicionais de procriação. Além do casal, pode, também, envolver o médico e em outras vezes um doador do material reprodutivo humano. Em algumas circunstâncias, a doação temporária do útero (mãe de aluguel ou mãe substituta).

Nos últimos cinco anos houve um aumento considerável no número de casais inférteis que procuram as clínicas de reprodução assistida. Para muitos deles, as técnicas de reprodução assistida são a última oportunidade para concretizar o sonho do filho biológico e geralmente elas são procu- 
radas após um longo período de tentativas por meio de outros recursos. Esses casais deparam-se, muitas vezes, com alguns problemas de ordem ética e legal, já que a área da reprodução assistida é permeada por muita polêmica, fazendo-se necessárias reflexões por parte da sociedade sobre o assunto.

Fortes (1993) considera que todas as inovações tecnocientíficas que vêm ocorrendo nesta área "trazem a imperiosa necessidade de profunda reflexão filosófica, ética e jurídica sobre as repercussões dessas nos direitos fundamentais que devem reger a vida humana” (p. 79). O autor acrescenta que tais conquistas científicas devem "visar o bem do ser humano”, portanto seus resultados e suas conseqüências devem ser limitados pela "manutenção das garantias e liberdades dos indivíduos” (p. 80).

Com o atual avanço tecnológico, a temática da infertilidade tem sido bastante abordada e as tecnologias reprodutivas estão sendo utilizadas por um grande número de pessoas. Pretendeu-se, com esta pesquisa, buscar mais explicações para esse tipo de opção, através da qual indivíduos inférteis tentam, de qualquer maneira, realizar o sonho de ter filhos biológicos.

A Teoria das Representações Sociais (TRS) foi utilizada como instrumento para a compreensão do processo de significação do filho biológico, considerando seu valor como instrumento de produção de conhecimento sobre objetos sociais relevantes.

Na área da saúde, a TRS tem sido uma ferramenta de muita importância, principalmente no que concerne ao processo de compreensão das concepções do senso comum sobre vários aspectos deste campo. Alguns estudos realizados em diversas áreas, focalizando aspectos da saúde, mostram que as concepções de saúde e de doença são construídas nos meios sociais conforme as relações estabelecidas em vários âmbitos: valores morais, crenças, religião, discurso médico, educação, situação financeira, além de outros (Menandro, 1995; Oliveira, Siqueira, \& Alvarenga, 1998; Trindade, 1998; Trindade \& Enumo, 2001).

Ao observar as representações que homens e mulheres envolvidos com a temática da infertilidade, constróem sobre o filho biológico, não se pode esquecer que as representações sociais da infertilidade são permeadas por crenças e simbologias em torno do significado do filho biológico para o casal e para a manutenção do próprio casamento.

Uma pesquisa de Trindade (1998), realizada com 50 mulheres que freqüentavam o Ambulatório de Infertilidade do Serviço de Pós-Graduação da Santa Casa de Misericórdia de Vitória/ES, mostrou que muitas mulheres procuravam a reversão de laqueadura. Segundo a autora, no caso da existência de um novo companheiro não se pode descartar a possibilidade de que elas estivessem satisfazendo um desejo dos maridos. Entretanto, ela enfatiza que

(...) em alguns grupos sociais e religiosos, a presença de filhos é condição básica para a concretização definitiva do casamento, satisfazendo suas funções biológica e social (...) Além disso é bastante antiga e difundida a crença feminina de que filhos biológicos, apenas por existirem, fortalecem os vínculos conjugais (p. 199).

Devido a todos os acontecimentos ocorridos na área da reprodução humana e às mudanças e conseqüências que eles acarretam na vida das pessoas, o objetivo dessa pesquisa foi investigar: a trajetória percorrida pelos casais que, tentando resolver o problema da infertilidade, submeteram-se à inseminação artificial, assim como o significado da presença de um filho biológico para esses casais.

Os objetivos específicos foram: descrever e analisar a trajetória de vida do casal a partir do momento em que foi constatada a infertilidade; identificar as representações sociais de filho biológico; identificar os significados que os casais atribuem à maternidade, paternidade e ao casamento; descrever e analisar o impacto do tratamento na vida dos casais.

\section{Método}

Participaram desta pesquisa cinco casais, sendo que todos estavam no primeiro casamento e não tinham filho biológico. Dois desses casais já haviam optado pela adoção.

A maioria dos entrevistados encontrava-se na faixa etária entre 37 e 48 anos. Somente um casal encontrava-se em outra faixa etária, a esposa estava com 28 anos e o marido tinha 34 anos.

O principal critério que nos conduziu para a escolha dos casais foi a condição de que eles já tivessem freqüentado alguma clínica de reprodução assistida e submetido-se à inseminação artificial. Optamos por uma amostra de casais que não tivessem obtido êxito em suas tentativas para engravidar.

Os dados foram coletados através de entrevistas semiestruturadas realizadas individualmente em local e horário apropriados, previamente marcados. Além dos dados pessoais, o roteiro abrangia questões relacionadas a: a) constatação da infertilidade, incluindo sentimentos, mudanças no relacionamento do casal, redes de apoio, entre outras questões; b) tratamentos realizados; c) significados de maternidade, paternidade, casamento e filho biológico.

Com permissão dos participantes, as entrevistas foram gravadas, com duração de aproximadamente setenta minutos cada uma. Posteriormente foram transcritas na íntegra pela própria pesquisadora e lidas exaustivamente, para auxiliar a compreensão sobre o conteúdo das mesmas. Após estas etapas, as falas dos participantes foram organizadas em unidades de significado, compatíveis com os objetivos da pesquisa. Entre as unidades de significado, foram consideradas, por exemplo, os antecedentes (acontecimentos anteriores à decisão pelo tratamento), o impacto da notícia de infertilidade, as redes de apoio, entre outras.

\section{Resultados e Discussão}

Apresentaremos a seguir os resultados de acordo com a seqüência das unidades de significado, com alguns recor- 
tes de transcrições de falas dos participantes com o intuito de melhor ilustrá-los.

\section{Perfil dos entrevistados}

Os entrevistados serão apresentados com nomes fictícios, para a manutenção do sigilo e também para facilitar o entendimento dos leitores. Cada casal terá uma letra que o identificará, sendo que o nome e o sobrenome de cada cônjuge serão iniciados pela mesma letra que identifica cada casal. Casal A: Adélia e Antônio Almeida; Casal B: Bianca e Beto Brito; Casal C: Carmem e Clóvis Cardoso; Casal D: Diana e Délio Duarte e Casal E: Elvira e Elton Esteves.

Todos os casais entrevistados residem em Vila Velha, Espírito Santo, sendo que quatro casais moram em bairros considerados de classe média alta e um casal mora em um bairro considerado de classe média baixa.

Adélia tem 41 anos, é cirurgiã dentista, casada com Antônio há quase oito anos. Este tem 48 anos, é empresário na área da construção civil, é italiano e vive no Brasil há alguns anos, longe de seus familiares.

Bianca tem 37 anos, é professora da pré-escola e estudante de Educação Artística. Seu marido, Beto, tem 40 anos, é administrador e trabalha numa empresa de metalurgia no mesmo município onde residem.

Carmem tem 40 anos, trabalha como auxiliar administrativo num órgão estadual, é estudante de Educação Artística e está casada há doze anos. Clóvis, seu marido, também tem 40 anos, é funcionário público federal.

Diana tem 28 anos, é professora e trabalhou nesta profissão até o ano de 2000. Na época da entrevista, estava trabalhando com transporte escolar e fazendo curso universitário. Está casada há dez anos com Délio, que tem 34 anos, é comerciante e trabalha numa agência de veículos de seu pai.

Elvira tem 42 anos, é farmacêutica bioquímica e comerciante. É casada há dezenove anos. Elton, seu marido, tem 47 anos, é cirurgião dentista.

\section{Antecedentes}

Entre os casais entrevistados, somente um e a esposa de um outro se referiram a um adiamento da gravidez no início do casamento. $\mathrm{O}$ casal Brito relatou ter protelado a gravidez para quando o marido estivesse no terceiro ano de faculdade. Adélia disse que havia protelado a decisão de ter filhos devido ao medo que tinha de perder sua liberdade. Porém, parou de utilizar métodos anticoncepcionais quando tinha um ano e meio de casada.

Délio contou que ele e sua esposa iniciaram as tentativas para engravidar logo no primeiro dia de casados. Os outros casais relataram que, no início do casamento, esperaram apenas por um pequeno período e, logo em seguida, começaram a tentar engravidar. Dos cinco casais entrevistados, quatro haviam utilizado algum método anticoncepcional no início do casamento, visto que não sabiam ter problema para engravidar. Somente o casal Duarte não utilizou nenhum desses métodos.
Após um período de tentativas para engravidar e sem obter êxito, os casais passavam a procurar por médicos, faziam exames, tentando encontrar uma solução.

Apesar de não ser este o procedimento padrão recomendado, em quatro casais os exames para investigar o motivo da infertilidade foi indicado primeiro para as mulheres. Tal procedimento parece apontar que, também entre os médicos, prevalece a idéia de responsabilização primeira da mulher quando se trata de problemas reprodutivos.

Nesse sentido, Bandeira (1999) argumenta que "na sociedade brasileira a definição de sexo feminino é, ainda, tradicionalmente referida à condição biológica e associada à esfera familiar da reprodução e, portanto, à maternidade..." (p. 184). Assim, pode-se observar que a infertilidade tem sido considerada "um problema feminino", apesar de alguns dados indicarem que os problemas de infertilidade podem afetar $15 \%$ dos casais, sendo que os fatores causais apresentam-se na mesma proporção entre homens e mulheres (Glina, 1999).

Soma-se a isso o fato ressaltado por Mason (1993) de que pouca atenção tem sido dada à experiência dos homens em relação à fertilidade. De acordo com a autora, eles são considerados como "meras figuras" e os assuntos relacionados às crianças e à concepção fazem parte do universo feminino. Geralmente, quando surge um problema de fertilidade, a responsabilidade recai sobre as mulheres.

Entre os cinco casais entrevistados, o problema de infertilidade apareceu da seguinte forma: em três casais o problema era da mulher, sendo que o mais grave foi o caso de Diana que precisou retirar o útero. Quanto aos outros dois casais, apesar de inicialmente ter sido encontrada alguma irregularidade na mulher, constatou-se depois que o problema estava principalmente no homem, como explicou Antonio: “Adélia tinha uns problemas técnicos e eu de repente... os meus 85 milhões de espermatozóides de um dia para o outro passaram pra 5 mil”.

\section{O impacto da notícia de infertilidade}

Conforme as respostas dos homens, a notícia de infertilidade não foi encarada com tranqüilidade. Por exemplo, Beto e Elton ficaram inconformados ao saber que eram como "uma árvore que não vai dar fruto".

Entre as mulheres, somente para Adélia este acontecimento não foi problemático, pois ela não pensava em ter filhos logo. Para as outras mulheres, a experiência foi muito ruim, causando sofrimento e frustração. Diana, por exemplo, contou que ficou arrasada, que queria morrer e ficava se perguntando por que aquilo havia acontecido com ela.

Esse sentimento parece não ser incomum; uma vez que, segundo Serafini, White, Petracco e Motta (1998), “a infertilidade é sentida como um 'defeito', provocando sentimento de desvalorização que se alastra por outros setores da vida” (p. 03).

Elton, inicialmente, ficou chocado com a notícia, posto que o casal havia feito alguns exames antes do casamento e nada de errado havia sido constatado. Para Elvira, foi difícil encarar a situação e ela ficava se perguntando se era diferen- 
te das outras, se conseguiria engravidar. Mas, com o diálogo que havia entre o casal, conseguiram enfrentar a situação.

Os dados encontrados nessa pesquisa corroboram as afirmações de Greil (1997) quando ressalta que a literatura apresenta um panorama da infertilidade como uma "experiência devastadora”, principalmente para as mulheres.

A infertilidade é uma situação difícil para muitos casais e pode gerar vários sentimentos, desde a vergonha perante as outras pessoas até uma sensação de anormalidade. Para as mulheres, o peso parece ser ainda maior porque, na maioria das vezes, elas são responsabilizadas pela tarefa da reprodução.

\section{Redes de apoio}

Os entrevistados encontraram maior apoio entre os familiares, mesmo porque esse assunto não era muito comentado em outros espaços de convivência. Segundo Beto, ele não comentava sobre o assunto com outras pessoas para não magoar a esposa, visto que ela poderia pensar que ele estava fazendo algum tipo de cobrança. Procurava apoio em Deus através de suas orações.

Carmem contou para toda a sua família e também para "alguns amigos, assim bem íntimos, amigos mesmo, amigos que eu pudesse assim contar". Seu marido, por não ter muito contato com parentes, disse que contou apenas para "alguns amigos".

A incapacidade de conceber é um assunto que geralmente fica mais restrito ao âmbito familiar, mantendo-se certa privacidade com relação a outras pessoas, até mesmo por haver certo temor por parte dos casais de que sejam feitas brincadeiras ou comentários com relação ao comportamento sexual do casal. Isso pode ser constatado por meio do relato de Elvira. De acordo com ela, alguns amigos de seu marido faziam comentários do tipo: “E ai, Elton, tá negando fogo?”. Tal tipo de cobrança coloca a pessoa numa situação delicada, uma vez que ela já está passando por um período difícil de sua vida e ainda se vê diante de comentários desagradáveis. Por esses e outros comentários, muitos casais preferem se resguardar, evitando falar sobre o assunto fora do âmbito familiar. Dessa forma, tentam preservar sua privacidade que, conforme Imber-Black (1994), "implica uma certa zona de conforto, livre do ingresso indesejado de outros” (p. 30).

A pesquisa de Trindade (1998) também aponta nessa direção, em que as mulheres entrevistadas indicaram como principais fontes de apoio a religião, o marido e a família, demonstrando "que se o problema relacionado à maternidade não é visível, em função das pressões sociais, é mantido em um nível privado e só é admitido às pessoas mais próximas e ao universo religioso" (p. 201).

\section{Explicação para o acontecimento}

As explicações que os casais deram para o problema de infertilidade foram, em sua maioria, relacionadas ao problema orgânico de um dos cônjuges. Uma outra explicação que também apareceu, embora com menor freqüência, foi a religiosa.
Segundo Antonio, havia uns "problemas técnicos" que impediam o casal de engravidar. Ele possuía um número reduzido de espermatozóides e Adélia não ovulava todos os meses. Ela afirmou que não sabia o porquê de não engravidar, pois não apresentava problemas.

O casal Brito relacionou o problema que aconteceu com a esposa à falha do médico que cuidava dela, em razão de que ele não pediu exames mais específicos que pudessem detectar seu problema no início e, assim, que ela pudesse ter mais chances de engravidar. Além disso, Beto referiu-se à questão religiosa. De acordo com ele, o casal é evangélico e, para eles, tudo na vida "tem um propósito de Deus".

Clóvis estava convicto de que a causa do problema de sua esposa era biológica, apesar de ter contado que a psicoterapeuta havia levantado a hipótese de alguma influência psicológica. Numa revisão de literatura sobre o impacto sócio-psicológico da infertilidade, Greil (1997) verificou que a hipótese psicogênica, isto é, aquela que se refere à possibilidade de a infertilidade ser proveniente de causas psicológicas, foi dominante no período de 1980 a 1990. Entretanto, o autor explica que mais recentemente essa literatura tem sido bastante criticada e rejeitada pela maioria dos pesquisadores.

A explicação de Diana foi baseada naquilo que o médico havia lhe dito, ou seja, que seu problema era congênito e hereditário. O casal Esteves também atribuiu sua infertilidade a problemas orgânicos, quando houve uma diminuição do número de espermatozóides de Elton. Quanto à Elvira não ficou bem esclarecido se ela realmente apresentava problema.

Percebemos que, de um modo geral, a explicação para a infertilidade entre os casais atrelou-se a problemas orgânicos e, conseqüentemente, a procura pela solução desses problemas foi através de tratamentos médicos. A crença nas soluções apresentadas pela medicina encontra-se bastante disseminada entre as pessoas. O médico geralmente é considerado a principal via para a solução do problema de infertilidade. Balen, Verdurmen e Ketting (1997), em um estudo com casais inférteis, constataram que entre as opções à disposição desses casais, a opção médica foi escolhida pela maioria deles. Outras alternativas só eram tentadas depois que as opções médicas haviam sido descartadas.

\section{Avaliação do processo}

Com relação à avaliação do processo de inseminação artificial, a maioria dos sujeitos citou certa "comercialização" existente nesse campo e uma "frieza" no relacionamento dos médicos com o paciente. Além disso, considerou o custo muito alto, o que impossibilita o acesso de muitos casais ao tratamento.

Quanto às informações recebidas previamente sobre o tratamento, a maioria dos sujeitos de nossa pesquisa disse que não foram suficientes. A fala de Bianca sobre a explicação que o médico havia dado, de que a probabilidade seria "zero ou cem", mostra que, pelo menos neste caso, não houve uma preocupação por parte do médico de esclarecer as verdadeiras probabilidades de sucesso do tratamento, dando uma explicação muito evasiva. 
A qualidade dos atendimentos também foi avaliada negativamente pela maioria dos entrevistados. Alguns disseram que os médicos eram muito rápidos em seus atendimentos, sem dar a devida atenção que este tipo de procedimento requer, o que pode ser exemplificado pela fala de Diana: “A jato, cinco minutos, podem ter trinta pessoas do lado de fora... porque o tratamento é caro e tudo, são pessoas que tão pagando muito caro, não é um INPS que tá lá. Pra ele entrar em cinco minutos, ainda do que tá se tratando e em cinco minutos ele resolver o problema”.

Somente o casal Esteves ficou totalmente satisfeito com o tratamento recebido. Este casal fez a inseminação artificial no período compreendido entre 1980 e 1990, com médicos pioneiros na área no Estado e que eram amigos do casal.

Alguns entrevistados disseram que o apoio de um psicólogo fez falta, uma vez que o médico não conseguia suprir essa parte, como exemplificado no relato de Bianca: “tem muitas pessoas pra atender, então ele (o médico) é muito rápido, ele é muito profissional”.

Os relatos fortalecem a presunção de que caberia, em situações dessa natureza, a atuação de um outro profissional, como o psicólogo que, juntamente com o médico, poderia oferecer um atendimento de maior qualidade para essas pessoas, fornecendo suporte para que os casais possam enfrentar a situação com menos ansiedade, sofrimento, vergonha e outros sentimentos que podem aparecer nessas circunstâncias. Conforme Corrêa (2001), a atuação de profissionais da área social ou psicológica, durante a aplicação das técnicas de reprodução assistida, "costuma ser exigida pelos comitês de bioética, sobretudo nos países da Europa” (p. 76).

\section{Casamento e mudanças no relacionamento do casal}

No tocante às mudanças ocorridas no relacionamento do casal após a constatação da infertilidade, alguns sujeitos disseram que não havia ocorrido nenhuma mudança, que tudo estava como antes. Entretanto, pareceu-nos que eles relacionavam mudança a uma desestabilização do casal, isto é, no aspecto negativo. Quando isso acontecia, refazíamos a pergunta, indagando se não havia ocorrido alguma mudança positiva. Neste caso, respondiam afirmativamente e acrescentavam que o casal havia se unido mais e que havia ocorrido um amadurecimento no relacionamento, como foi mencionado por Carmem: “... acho que de uma certa forma a gente veio amadurecendo mais, conversando mais o problema...”.

Greil (1997), numa revisão de literatura sobre infertilidade e distress psicológico, citou que, num estudo que havia feito anteriormente, muitos casais entrevistados haviam relatado que a infertilidade os tinha aproximado. Gianórdoli (2000), em pesquisa com casais em que um dos cônjuges havia enfartado, constatou através das falas das mulheres que houve um "fortalecimento da união e da proximidade do casal, principalmente em função da possibilidade da perda de vida” (p. 199). Esses dados nos levam a concluir que, em situações difíceis de vida, os membros do casal geralmente procuram apoiar-se mutuamente.
Nem sempre o fortalecimento do vínculo aconteceu sem problemas entre os casais entrevistados. No caso do casal Brito, por exemplo, a situação de infertilidade ocasionou alguns problemas, principalmente quando Beto disse, na frente de outras pessoas, que, se soubesse que Bianca não poderia ter filhos, não teria se casado com ela, o que a deixou muito magoada. Cabe ressaltar que este fato não foi citado por ele; pelo contrário, Beto afirmou que não comentava o problema com outras pessoas para não magoar a esposa.

Verificamos que, no relacionamento de um dos casais entrevistados, não havia acontecido uma aproximação após a constatação da infertilidade. Segundo Délio, a mudança no seu casamento foi para pior e contou que sua esposa estava com problemas. Diana falou que havia algumas coisas entre o casal que precisavam ser resolvidas. O casal apresentou posturas diferentes com relação ao casamento, demonstrando que havia outros problemas anteriores à infertilidade. Nesse sentido, parece que, instaurada a situação de infertilidade, as conseqüências no relacionamento do casal poderão ser motivadas não somente pela situação em si. Outras relações, anteriormente estabelecidas entre eles, também poderão influenciar os acontecimentos após a experiência traumática, podendo resultar num fortalecimento do casamento ou, por outro lado, causar um distanciamento do casal e, até mesmo, acarretar uma ruptura no casamento.

\section{Maternidade e paternidade}

As respostas dos entrevistados referentes ao significado da maternidade e da paternidade remetem aos padrões tradicionais. A maternidade foi citada como algo mais envolvente do que a paternidade, em que "a mulher se dá para os filhos” (Beto). Foi considerada também como "uma realização para a mulher” (Carmem) e uma dádiva que só a mulher pode ter. Além disso, ela seria muito importante para a mulher "porque sai de dentro dela” (Clóvis) e, de acordo com Beto, os filhos têm mais importância para a mulher do que para o homem. A maternidade apareceu, na maioria das entrevistas, como parte da estrutura identitária das mulheres, isto é, à medida que elas se tornam mães, elas se tornam "inteiras”, “completas”, o que é exemplificado pelas diferenças que Antônio aponta entre paternidade e maternidade. Ao referirse à paternidade, enfatizou o lúdico e a aprendizagem que a convivência com o filho propicia. Quanto à maternidade, explicou que ela proporciona "um crescimento e amadurecimento” para a mulher. Nesse sentido, parece que a formação feminina passa necessariamente pela maternidade.

Tais representações da maternidade podem ser explicadas pelo processo de socialização das mulheres, em que estas são, “desde muito cedo, convencidas de que a maternidade é o único caminho para sua realização pessoal e que cabe a elas a responsabilidade pelo sucesso da maternidade” (Trindade, 1993, p. 538).

Com relação ao significado da paternidade, outros elementos apareceram com maior importância, uma vez que o filho não foi, nesse caso, considerado como forma de "realização" ou "complemento", como fora para as mulheres. Sua 
importância apareceu na relação pai e filho, ou seja, a atenção e o carinho dispensados pelo pai, a ajuda no crescimento do filho e até como companhia para as brincadeiras.

\section{Representações sociais de filho biológico}

O filho biológico, de um modo geral, apareceu como um objetivo de todos os casais entrevistados, sendo que as mulheres demonstraram maior interesse. A procura por soluções para atingir essa meta iniciou-se, na maioria das vezes, por elas.

Os elementos de representação social de filho biológico que apareceram fortemente nas entrevistas foram: sangue do meu sangue (o filho sendo parte do casal e a ênfase na importância da gestação); a descendência, dando continuidade à família; as semelhanças físicas entre pais e filhos; e a pressão social influenciando as decisões do casal.

Dos cinco homens entrevistados, dois deles, apesar de também terem tentado o filho biológico utilizando as tecnologias de reprodução assistida, relataram não ter tido grandes problemas para desistir daquele objetivo. Para Antônio, a paternidade biológica não era tão importante, ele queria ser pai, "independentemente de como esse filho viesse". Com relação ao casal Esteves, a decisão pela adoção partiu de Elton, que relatou não ter tido dificuldades.

Para os três homens entrevistados que não recorreram à adoção, o filho biológico tinha uma importância maior, principalmente pelo fato de dar continuidade à sua descendência e ser parte do casal (sangue do meu sangue). Conforme Beto, era importante "deixar sua marca no mundo" e enfatizou a importância de o próprio casal gerar o filho; pois, dessa maneira, o filho será "parte do corpo da mulher".

Para Carmem, o filho biológico "tem toda importância”, principalmente com relação às características semelhantes entre pais e filhos. Quanto a uma possível adoção, disse não se sentir preparada ainda, apesar de não ter descartado a possibilidade.

A preocupação com as semelhanças físicas entre pais e filhos, encontrada nas falas de alguns de nossos entrevistados, é citada por Weber (1999) como uma valorização da "cultura do sangue", em que "o ser humano... tem uma grande necessidade de encontrar e enfatizar as semelhanças físicas com os filhos. As pessoas sentem-se orgulhosas quando alguém diz que o filho 'é a sua cara'!” (p. 126). O que ficou evidente com nossa entrevistada Carmem, que disse categoricamente que a importância maior são as características semelhantes do filho com os pais: “... não tem aquela coisa, tal pai, tal filho? No andar, na fisionomia... eu adoraria ter um filho parecido comigo ou com o Clóvis”.

A importância da vinculação genética constatada em nossa pesquisa também foi observada por Corrêa (2001), num estudo realizado com mulheres que passaram pela fertilização in vitro, em que a autora concluiu que o "filho é percebido como um reflexo dos pais não somente no sentido social do termo, mas também e sobretudo como um reflexo biológico, representação que as tecnologias reprodutivas tendem a reforçar” (p. 144, negritos nossos).

\section{Considerações finais}

Semelhante à maioria dos trabalhos nessa área, este estudo focalizou casais que queriam engravidar, mas encontraram pelo caminho um obstáculo: a infertilidade. Na tentativa de gerar um filho biológico, esses casais procuraram, como muitos outros, por tratamento em clínicas de reprodução assistida.

Percebemos claramente que os entrevistados atribuíram grande importância ao filho biológico, fato que pôde ser observado nas entrevistas e na análise dos dados coletados que mostram como elementos de representação social do filho biológico: "sangue do meu sangue" (o filho sendo parte do casal e a importância da gestação), a descendência, as semelhanças físicas e a pressão social, indicando que o filho biológico estrutura a identidade feminina e atesta a virilidade masculina.

Considerando que as representações sociais orientam as práticas, a força destas representações pode explicar a busca por tratamentos emocionalmente desgastantes, caros e que, apesar de negativamente avaliados pelos participantes, foram procurados mais de uma vez.

Mesmo aqueles casais que já haviam adotado, demonstraram que ter um filho biológico tinha sido seu objetivo um dia e que, por razões diversas, resolveram a questão da maternidade e da paternidade através da adoção. Aqueles que não decidiram o que irão fazer parecem ainda dar prioridade ao filho biológico, talvez por ainda não se sentirem preparados para a adoção ou porque preferem continuar tentando realizar este sonho. Outras alternativas, como a opção por não ter filhos, pareceram não estar incluídas nos projetos desses casais.

Este trabalho abrangeu uma pequena parcela de algo muito mais amplo, que são as tecnologias reprodutivas e tudo que as envolve. Sabemos que muito há para se pesquisar na área, como por exemplo: a situação da mulher infértil que não tenta nenhum tratamento; mulheres que adotam crianças sem ter se submetido a nenhum tratamento para infertilidade; mulheres que optam pela produção independente. Há também a necessidade de estudos interdisciplinares envolvendo disciplinas como Direito, Ética e outras, posto que a complexidade desse campo está além dos limites da Medicina.

\section{Referências}

Arilha, M. (1996). Desejo da maternidade, tecnologias conceptivas e o estado: rápidas considerações. In L. Scavone (Org.), Tecnologias reprodutivas (pp. 199-204). São Paulo: Editora UNESP.

Ávila, M. B. M., \& Corrêa, S. (1999). O movimento de saúde e direitos reprodutivos no Brasil: revisitando percursos. In L. Galvão \& J. Díaz (Orgs.), Saúde sexual e reprodutiva no Brasil (pp. 70-103). São Paulo: Hucitec.

Balen, F., Verdumen, J., \& Ketting, E. (1997). Choices and motivations of infertile couples. Patient Education and Counseling, 31, 19-27.

Bandeira, L. (1999). Relações de gênero, corpo e sexualidade. In L. Galvão \& J. Díaz (Orgs.), Saúde sexual e reprodutiva no Brasil (pp. 180-197). São Paulo: Hucitec. 
Collucci, C. (2000). Quero ser mãe - histórias reais de mulheres que engravidam com a ajuda da ciência. São Paulo: Palavra Mágica.

Corrêa, M. V. (2001). Novas tecnologias reprodutivas - limites da biologia ou biologia sem limites? Rio de Janeiro: Editora UERJ.

Fonseca, L. C. L. (1998). Paternidade adolescente: da investigação à intervenção. In. M. Arilha, S. G. U. Ridenti, \& B. Medrado (Orgs.), Homens e masculinidades: outras palavras (pp. 185-214). São Paulo: Editora 34.

Fortes, P. A. C. (1993). Reflexões sobre a procriação artificial e os direitos das crianças. Revista Brasileira de Crescimento e Desenvolvimento Humano, III(2), 79-85.

Gianórdoli, I. (2000). O que fazer quando o coração aperta? A relação conjugal e suas transformações pós-infarto. Dissertação de Mestrado em Psicologia não-publicada, Universidade Federal do Espírito Santo, Vitória.

Glina, S. (1999). Ainda existe infertilidade masculina? Revista Medicina - Conselho Federal, Ano XIV, n. 102, 2.

Greil, A. L. (1997). Infertility and psychological distress: a critical review of the literature. Social Science and Medicine, 45(11), 1679-1704.

Imber-Black, E. (1994). Os segredos na família e na terapia familiar. Porto Alegre: Artes Médicas.

Mason, M-C. (1993). Male infertility - men talking. Londres: Routledge.

Menandro, M. C. S. (1995). Convivência familiar com o afetado por distrofia muscular de Duchene: da comunicação do diagnóstico às estratégias de enfrentamento. Dissertação de Mestrado em Psicologia não-publicada, Universidade Federal do Espírito Santo, Vitória.

Oliveira, D. C., Siqueira, A. A. F., \& Alvarenga, A. T. (1998). Práticas sociais em saúde: uma releitura à luz da teoria das Representações Sociais. In A. A. P. Moreira \& D. C.Oliveira (Orgs.), Estudos interdisciplinares de representação social (pp. 163-190). Goiânia: AB Editora.
Rocha-Coutinho, M. L. (1994). Tecendo por trás dos panos: a mulher brasileira nas relações familiares. Rio de Janeiro: Rocco.

Schaffer, J. A. \& Diamond, R. (1994). Infertilidade: dor pessoal e estigma secreto. In E. Imber-Black (Org.), Os segredos na família e na terapia familiar (pp. 113-127). Porto Alegre: Artes Médicas.

Serafini, P., White, J., Petraco, A., \& Motta, E. (1998). O bê a ba da infertilidade. São Paulo: Organon.

Souza, M. C. M. (1995). Novas tecnologias reprodutivas: direitos reprodutivos e bioética: a inseminação artificial na constituição de famílias alternativas. Documenta (UFRJ), III(6), 77-87.

Tanaka, A. C. A., \& Alvarenga, A. T. (1999). Tecnologias e medicalização na concepção e anticoncepção. In L. Galvão \& J. Díaz (Orgs.), Saúde sexual e reprodutiva no Brasil (pp. 198-208). São Paulo: Hucitec.

Trindade, Z. A. (1993). As representações sociais e o cotidiano: a questão da maternidade e da paternidade. Psicologia: Teoria e Pesquisa, 9(3), 535-546.

Trindade, Z. A. (1998). Em busca da maternidade: dilema reprodutivo de mulheres inférteis. In A. S. P. Moreira \& D. C. Oliveira (Orgs.), Estudos interdisciplinares de representação social (pp. 191-203). Goiânia: AB Editora.

Trindade, Z. A., \& Enumo, S. R. F. (2001). Representações sociais de infertilidade feminina entre mulheres casadas e solteiras. Psicologia: Saúde \& Doenças, 2(2), 05-26.

Tubert, S. (1996). Mulheres sem sombra - maternidade e novas tecnologias reprodutivas (trad. Graciela Rodriguez). Rio de Janeiro: Record/ Rosa dos Tempos.

Weber, L. N. D. (1999). Laços de ternura - pesquisas e histórias de adoção. Curitiba: Juruá.

Ana Maria Monteiro Borlot é mestre em Psicologia pela Universidade Federal do Espírito Santo. Endereço para correspondência: Rua Rio Branco, 48, Praia da Costa; Vila Velha, ES; CEP 29101-130. Fone: (27) 33499365. Fax: (27) 3239-2620. E-mail: ana.borlot@terra.com.br

Zeidi Araújo Trindade, doutora em Psicologia Experimental pela Universidade de São Paulo, é professora no Departamento de Psicologia Social e do Programa de Pós-graduação em Psicologia, Universidade Federal do Espírito Santo. 